\title{
Controle do Ambiente de Integração de Sistemas em um Órgão Público
}

\author{
Wellington M. Anastácio ${ }^{1}$, Edmir P. V. Prado ${ }^{1}$, Violeta Sun ${ }^{1}$, Marcelo Fantinato ${ }^{1}$ \\ ${ }^{1}$ Escola de Artes, Ciências e Humanidades - Universidade de São Paulo (USP) \\ Rua Arlindo Béttio, 1000 - CEP: 03828-000- São Paulo - SP - Brazil \\ wellingtonmontefuscodusp.br, eprado@usp.br, violeta@usp.br, \\ m. fantinatodusp.br
}

\begin{abstract}
Control systems integration (IS) information is, to the electronic government, a challenging, interesting and little explored issue in Brazil. This case study explores this environment in a public agency of Brazil that is reference in information technology. Key contributions of this paper are: (1) presenting a model of IS control process that promotes standardization, systematic communication, knowledge management, division of responsibilities, continuous improvement and; (2) identification that changing requirements is the most problematic issue for physical design phases of integrations.
\end{abstract}

Resumo. Controlar a integração de sistemas (IS) de informação é, para o governo eletrônico, uma questão desafiadora, interessante e pouco explorada no Brasil. Este estudo de caso explora a questão em um órgão público brasileiro referência em tecnologia da informação. São contribuições chaves desse artigo: (1) apresentação de um modelo de processo de controle de IS que promove padronização, comunicação sistemática, gestão de conhecimento, divisão de responsabilidades e melhoria contínua; (2) identificação que a mudança de requisitos é o fator mais problemático para as fases de projeto físico das integrações.

\section{Introdução}

A prática da IS no governo contribui para a resolução de problemas de redundância e inconsistência de dados. Outros problemas comumente destacados são serviços com responsabilidade compartilhada, falta de conectividade entre aplicações, falta de proteção aos dados do cidadão, alto custo de operação de sistemas, alto custo de manutenção de sistemas e falta de integridade nos dados [Kamal e Themistocleous 2006].

Por outro lado, muitas barreiras desafiam as organizações públicas na implantação de serviços de governo eletrônico. Huang e Bwoma (2003) destacam a falta de capacidade de gerenciar projetos de tecnologia de informação, conflitos entre expectativa e realidade, resistência dos empregados da organização, frameworks obsoletos para inovação, gestão inadequada da informação e uso inadequado de dados relevantes.

Compreender como controlar a IS de informação em órgãos públicos contribui para a superação de barreiras gerenciais, promove a efetividade na produção de serviços de governo eletrônico e auxilia no dimensionamento de esforços referentes a sistemas de informação. 
Dentro desse contexto, este artigo tem como objetivo analisar os processos de controle relacionados às atividades de IS. A pesquisa foi desenvolvida por meio de um estudo de caso em um órgão público. Espera-se que os resultados possam contribuir para o conhecimento e aperfeiçoamento dos processos de controle da IS no governo brasileiro.

\section{Fundamentação Teórica}

Organizações públicas são sistemas complexos e com alta aplicação de burocracia no funcionamento [Saraiva e Capelão 2000]. Rossetto, Orth, e Rossetto (2004) destacam que organizações públicas apresentam fidelidade às regras e rotinas, supervalorização da hierarquia, apego ao poder e paternalismo nas relações.

Essas características se refletem na postura dos empregados, gerando reflexos na forma da organização lidar com inovações, mudanças e processos internos [Santos et al. 2012]. Por isso, e pelos objetivos desta pesquisa, compreender como controlar a IS nas organizações públicas requer o valimento dos processos organizacionais que a subordinam.

\subsection{Processos Organizacionais}

Nas organizações existem processos que cumprem determinadas funções de negócio. Esses "processos de negócio" representam um conjunto de atividades que, quando executadas juntamente, produzem um resultado de valor para o cliente [Hammer e Champy 1993].

A WfMC (1999) define processo de negócio como um conjunto de atividades que realizam um objetivo de negócio ou atendem uma determinada política. Essas atividades normalmente se desenvolvem no contexto da estrutura organizacional e estabelecem relacionamentos entre as estruturas funcionais da organização.

Mili et al. (2010) sintetizam que processos de negócio são executados por atores que seguem regras particulares, consumindo recursos e produzindo outros. As atividades do processo podem ser engatilhadas por eventos e podem gerar eventos. Os atores operam em um contexto com fronteiras organizacionais e em atividades que podem depender da realização de outras atividades.

Inicialmente, as teorias administrativas gerenciavam as divisões de uma cadeia de comando hierarquizada, com tratamento de custo, fluxo de trabalho e forma de comunicação de cada divisão de maneira isolada. Com o redesenho de processos de negócio, o foco administrativo mudou para o processo como um todo, tratando, simulando e procurando formas de aperfeiçoamento na transação de negócio de ponta a ponta [Hammer e Champy 1993].

Mili et al. (2010) consideram que diferentes processos de negócio podem cruzar diferentes fronteiras organizacionais de diferentes formas, abrindo margem para estruturas organizacionais inovadoras, tais como as organizações orientadas a projetos e as organizações em estrutura matricial.

De qualquer forma, o redesenho dos processos de negócio, a evolução de novas tecnologias e o comércio eletrônico renovaram o interesse na modelagem de processos como pré-requisito para a melhoria contínua. Assim, processos de negócio passaram a 
priorizar a execução computacional nas atividades em que os seres humanos executavam de maneira menos eficiente [Hammer e Champy 1993].

Hammer (1990) ressalta que em muitos cenários a evolução dos processos e dos sistemas de informação ocorrem de maneira improvisada, criando íntimas relações com a organização. Por isso e por todos os potenciais benefícios do redesenho de processos de negócio, avaliar e medir impactos nos processos de negócio no qual uma IS se proponha a gerar melhorias contribui para o alcance do objetivo.

\subsection{Integração de Sistemas}

A IS é um fenômeno que ocorre quando mais de um sistema de informação colaboram eletronicamente para atingir um objetivo. Segundo Sommerville e Melnikoff (2003), essa colaboração pode ocorrer entre sistemas de informação diferentes ou ainda entre módulos de um único sistema quando este é muito grande, tal como os sistemas ERP.

Sommerville e Melnikoff (2003) destacam que uma das dificuldades da IS reside nos testes de integração. Nestes testes, quando as interações entre os componentes do sistema resultam em saídas anômalas, raramente a origem do erro fica em evidência. Assim, mesmo utilizando abordagens como testar uma configuração mínima e, em seguida, adicionar componentes até a localização do erro, testar as integrações pode ser muito complexo.

Componentes dispersos podem ser necessários para testar um único recurso. Os testes podem revelar erros nas interações entre esses componentes e em outras partes do sistema. O reparo pode afetar ou colocar em evidência erros em componentes dependentes do reparado. Novos componentes que são integrados e testados podem modificar o padrão das interações já testadas. Erros que não haviam sido detectados nos testes de configuração mais simples podem surgir [Sommerville e Melnikoff 2003].

Além disso, diferentes funções organizacionais podem ser responsáveis por diferentes componentes do sistema, tornando a resolução de problemas de IS muito mais ampla. Nesse caso, Kamal e Themistocleous (2006) considera que a resolução de problemas extrapola questões sintáticas, passando a envolver a análise de frameworks estratégicos de colaboração, redesenho de processos de negócio, tratamento da resistência à mudança, política de interoperabilidade e a expertise de gerentes em IS.

\subsection{Apresentação da Empresa}

Esta pesquisa se desenvolveu em uma empresa pública brasileira responsável pela administração da TI em dezenas de órgãos governamentais. Esta empresa foi criada há mais de três décadas e integra vários sistemas e bases de dados de diferentes fornecedores, atendendo diversas esferas do governo. Ela possui mais de três mil empregados, e realizou inúmeras ações integradoras na administração pública federal e em iniciativas de governo eletrônico.

O parque computacional instalado dessa empresa é significativo. Ela possui mais de quinhentos servidores de baixa plataforma, além de ambiente de alta plataforma. Os dados estão armazenados em múltiplos bancos de dados, espalhados em mais de um centro de processamento de dados.

A empresa está estruturada em diretorias funcionais. Entre elas, destacam-se para o objetivo desta pesquisa a diretoria responsável pelo relacionamento com clientes 
e a diretoria especializada no desenvolvimento de soluções de TI. Subordinada à primeira há superintendências responsáveis por carteiras de clientes. Cada cliente, a depender do órgão público em que trabalha e de sua atividade principal, fica sob a gestão de unidades de atendimento de uma superintendência. Estas unidades possuem especialistas no negócio do cliente, que encaminham demandas de construção ou manutenção de sistemas às equipes especialistas em engenharia de software.

$\mathrm{Na}$ diretoria responsável pelo desenvolvimento de soluções de TI ficam as equipes especializadas em engenharia de software. Estas equipes ficam subordinadas a uma superintendência especializada na execução dos processos de engenharia. Nessa superintendência, o trabalho é dividido entre departamentos, sendo que os departamentos possuem analistas responsáveis pela análise de requisitos, projeto físico de sistemas, programação e teste de software.

\section{Método da Pesquisa}

Esta pesquisa busca analisar os processos de controle relacionados às atividades de IS, estudando eventos contemporâneos de difícil controle em laboratório. Como consequência, a estratégia de estudo de caso se mostra apropriada [Yin 2005]. fases:

Os procedimentos metodológicos desta pesquisa podem ser agrupados em seis

a) Revisão bibliográfica. A pesquisa bibliográfica possibilitou a elaboração de um roteiro de análise para as fases subsequentes e precedeu ao levantamento de fatos e documentos. Esta fase ocorreu entre julho de 2010 e janeiro de 2011.

b) Escolha do objeto de estudo. A partir da estrutura organizacional da empresa e das informações sobre projetos de IS foi selecionada uma área específica, na qual se desenvolvia um projeto de construção de sistema integrado com características alinhadas aos objetivos da pesquisa.

c) Mapeamento dos processos institucionais de IS. A partir do projeto selecionado, por meio de consulta a documentos institucionais e entrevistas não estruturadas, foi mapeado o processo de controle da IS nesse ambiente. As entrevistas envolveram o líder (gestor) do projeto, dois profissionais de análise de requisitos e dois profissionais de análise de projeto físico, que validaram o modelo. Esta etapa ocorreu em fevereiro de 2011, na cidade de São Paulo.

d) Mapeamento e padronização dos processos empíricos de IS. Através de entrevistas não estruturadas envolvendo o líder do projeto, dois analistas de requisitos e dois analistas de projeto físico, foram identificadas dificuldades e oportunidades de melhoria. Considerando estas e o objetivo de alcançar um modelo mais rico para o controle da IS, elaborou-se um modelo complementar ao institucional, documentando e padronizando atividades de IS anteriormente realizadas de forma ad hoc. Também se elaborou um plano para execução da mudança. O modelo complementar e o plano de mudança foram validados pelos entrevistados e, por fim, uma ferramenta de apoio, concentradora das informações de controle da IS, foi desenvolvida. Esta etapa ocorreu entre março e maio de 2011, na cidade de São Paulo.

e) Avaliação dos resultados. Após sete meses da implantação do modelo complementar, avaliou-se o uso do modelo, da ferramenta de apoio e as lições aprendidas. A avaliação considerou a consulta do histórico de eventos de IS na 
ferramenta de apoio, a aplicação de questionário, entrevistas não estruturadas e a observação. O questionário perguntou sobre as dificuldades na IS, as oportunidades de melhoria e o uso da ferramenta. As respostas do questionário foram tratadas através de análise temática do conteúdo. Esta etapa ocorreu em dezembro de 2011, na cidade de São Paulo.

f) Relatório final: Foram discutidos os resultados obtidos e feitas as considerações finais. Esta etapa ocorreu em janeiro de 2012.

As fases "a", "b", "c" e "d" envolveram a participação de um pesquisador mestrando em sistemas de informação e um pesquisador doutor em administração. As fases "e" e "f" contaram com dois pesquisadores adicionais, um doutor em ciência da computação e outro em administração.

\subsection{Objeto de Estudo}

O objeto de estudo na organização pública em questão é um sistema de informação integrado e que estava em etapa de construção. Esse sistema tinha integração com mais de 30 sistemas externos. Cada módulo desse sistema integrado foi desenvolvido por um projeto em separado, ou seja, cada módulo possuía um líder e uma equipe de analistas de sistemas para especificação e implementação de funcionalidades. Estava previsto, ao término da implantação do sistema de informação integrado, a descontinuação de alguns sistemas legados. Além disso, outros sistemas legados, não descontinuados, passariam a acessar o novo sistema de informação integrado.

A equipe era composta por mais de 12 especialistas em desenvolvimento de sistemas, sendo dez especialistas em projetos físicos e dois em requisitos de sistemas de informação. Além disso, a maior parte dos projetistas realizavam também atividades de implementação.

As observações se focaram nos controles aplicados sobre os módulos do sistema em construção que se integravam, bem como nos controles aplicados sobre módulos que se integravam a sistemas legados. Além disso, também foram observados os processos organizacionais que subordinavam a equipe de desenvolvimento.

\section{Análise dos Resultados}

Esta seção apresenta: mapeamento dos processos institucionais de IS; dificuldades e oportunidades de melhoria; mapeamento e padronização dos processos empíricos de IS e; resultados.

\subsection{Mapeamento dos Processos Institucionais de IS}

O processo de controle da IS inicialmente encontrado se subordinava a dois processos corporativos maiores:

a) Processo de negócio da empresa. Este tem a finalidade de registrar o atendimento à solicitação de um cliente, administrar o andamento de demandas derivadas do atendimento e promover soluções.

b) Desenvolvimento de sistemas de informação. Este tem a responsabilidade de realizar as etapas de engenharia de software que implementam as integrações a serem homologadas pelo cliente. 
Quando uma nova integração é solicitada por um cliente, primeiramente a solicitação de atendimento é registrada. Registram-se também as ações relevantes ao atendimento e um registro de controle referente ao perfil do cliente.

Com base na solicitação de atendimento, na análise da satisfação do cliente e na avaliação de um analista de negócio são identificadas oportunidades de melhoria. Essas oportunidades são negociadas com o cliente e tratadas sob a forma de uma demanda de serviço.

Quando essa demanda é concluída, busca-se identificar novas oportunidades de negócio, registrando em atas as negociações que subsidiarão o planejamento da empresa na aquisição e alocação de hardware e software. Periodicamente é aferida a satisfação do cliente por meio de pesquisas de satisfação e verificação das ferramentas que interagem com o cliente.

A demanda é gerenciada entre sua abertura e fechamento. Durante esse período, ocorrem interações com as equipes de desenvolvimento de sistemas. Quando uma demanda de integração é aberta, a equipe de desenvolvimento envolvida deve avaliar a pertinência e conceber a solução. Essas atividades envolvem estimar o esforço de trabalho a ser realizado, modelar o negócio do cliente, elaborar um plano de negócio, homologar e implantar a solução.

$\mathrm{O}$ atendimento da demanda é o ponto onde o negócio se integra com a engenharia de software. A demanda cria solicitações de serviço que justificam a criação de projetos de software.

A figura 1 ilustra as principais etapas ocorridas no processo. Existe ainda uma importante etapa de testes integrados que ocorre após a conclusão da integração entre os sistemas. Essa etapa tem como objetivo antecipar a detecção de erros que poderiam ocorrer nos ambientes de homologação e produção, reduzindo, assim, os custos de manutenção. Optou-se por não incluir esta etapa no mapeamento porque, na perspectiva técnica, ela repete execuções que supostamente já deveriam ter sido tratadas pelos implementadores. Maiores explorações podem se mostrar interessantes em trabalhos futuros.

\subsection{Dificuldades e Oportunidades de Melhoria}

Os seguintes fatores foram identificados como dificuldades e oportunidades na IS:

a) identificação de serviços de sistemas que podem ser reutilizados na implementação de mais de uma especificação de requisitos;

b) regras de negócio que mudam durante ou após a fase de projeto físico;

c) requisitos que mudam durante ou após a execução de projeto físico de integração;

d) necessidade de conhecimento da organização e do negócio por parte dos especialistas em desenvolvimento de software durante projeto físico das integrações;

e) falta de documentação adequada referente aos serviços de integração entregues;

f) realização de testes integrados;

g) longa espera pela disponibilização dos serviços de integração; 
h) desvios de comunicação na evolução dos trabalhos de IS.
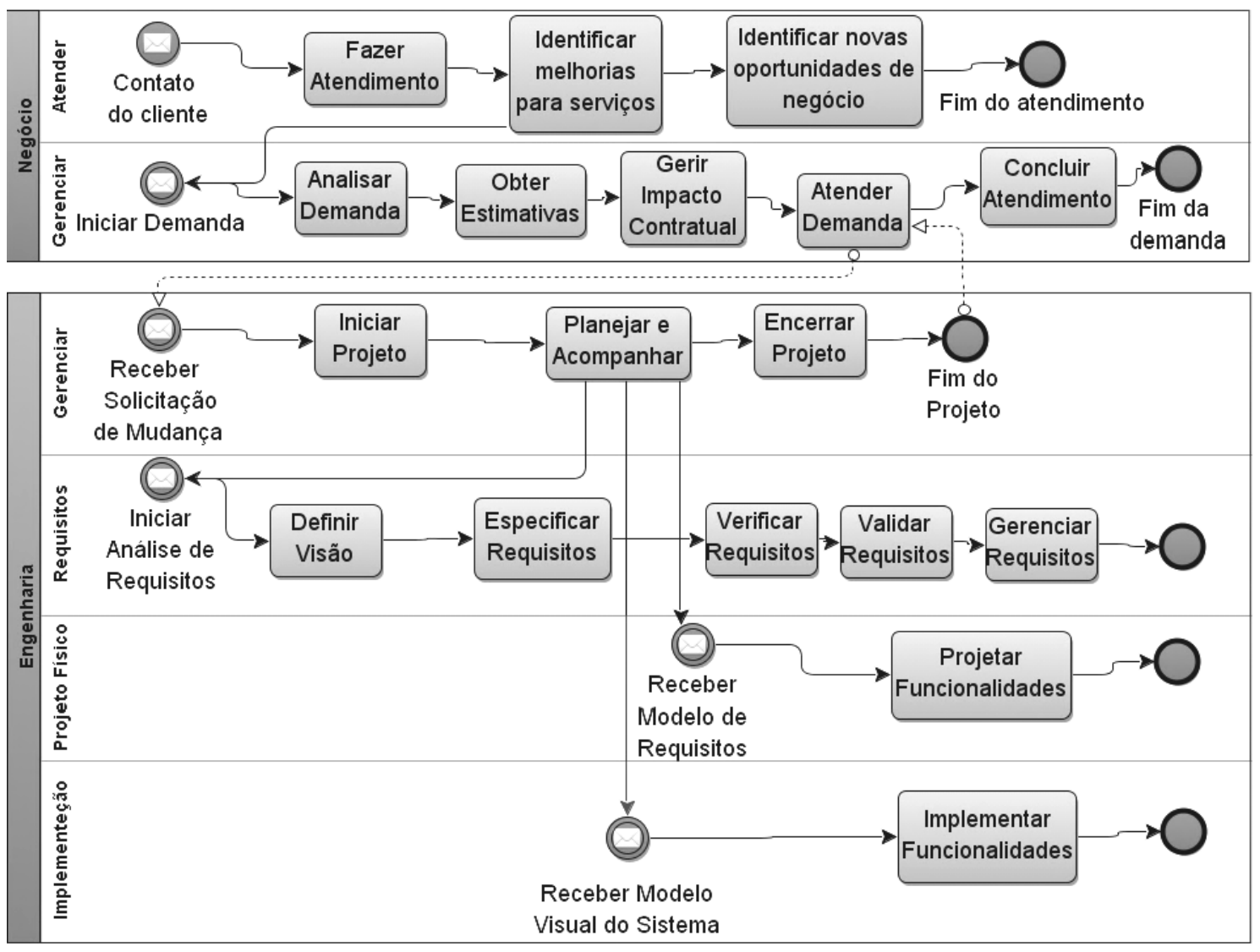

Figura 1. Processo institucional

\subsection{Mapeamento e padronização dos processos empíricos de IS}

Considerando os problemas detectados e os objetivos desta pesquisa, elaborou-se um modelo complementar ao processo institucional, transparecendo e padronizando atividades de IS anteriormente realizadas de forma ad hoc. Este modelo passou a ser, na perspectiva dos integrantes da equipe, responsável pelo controle efetivo da IS no ambiente específico do projeto em estudo.

Assim, foram prescritos três processos: gestão de mudança de requisitos e solicitação de serviços (GMRSS); gestão de consumo dos serviços (GECOSE) e; gestão de atendimento a solicitações de serviços (GASS).

a) Gestão de mudança de requisitos e solicitação de serviços (GMRSS). O processo GMRSS, apresentado na figura 2, retrata as atividades necessárias para garantir que uma necessidade de integração não deixe de ser solicitada à equipe de desenvolvimento responsável pela disponibilização do serviço de integração (Service Provider). Também cabe ao processo garantir que uma integração descartada não deixe de ser comunicada às partes interessadas. Podemos ilustrar o uso deste processo da seguinte maneira: Quando uma especificação de requisitos sofre uma mudança, é possível que essa mudança tenha impacto nas integrações. Quando há impacto, o gestor técnico necessitará comunicar as partes interessadas o impacto (por exemplo: se um analista de projetos físicos estiver trabalhando em uma integração na qual o analista de requisitos determinou que será substituída por outra, ao saber dessa notícia o analista de 
projetos físicos pode suspender os esforços nessa atividade, evitando o trabalho desnecessário). $\mathrm{O}$ analista de requisitos deve avisar o gestor técnico que alguns documentos de requisitos precisam ser reavaliados. Caso ele esqueça, a auditoria semanal identificará arquivos que sofreram modificações. Assim, o gestor técnico poderá interagir com esses analistas, identificando modificações e possíveis impactos nas integrações. Quando existe o impacto (novas integrações, integrações descartadas ou mudança nas interfaces), um catálogo de serviços é gerado, informando todas as partes interessadas envolvidas nas mudanças.

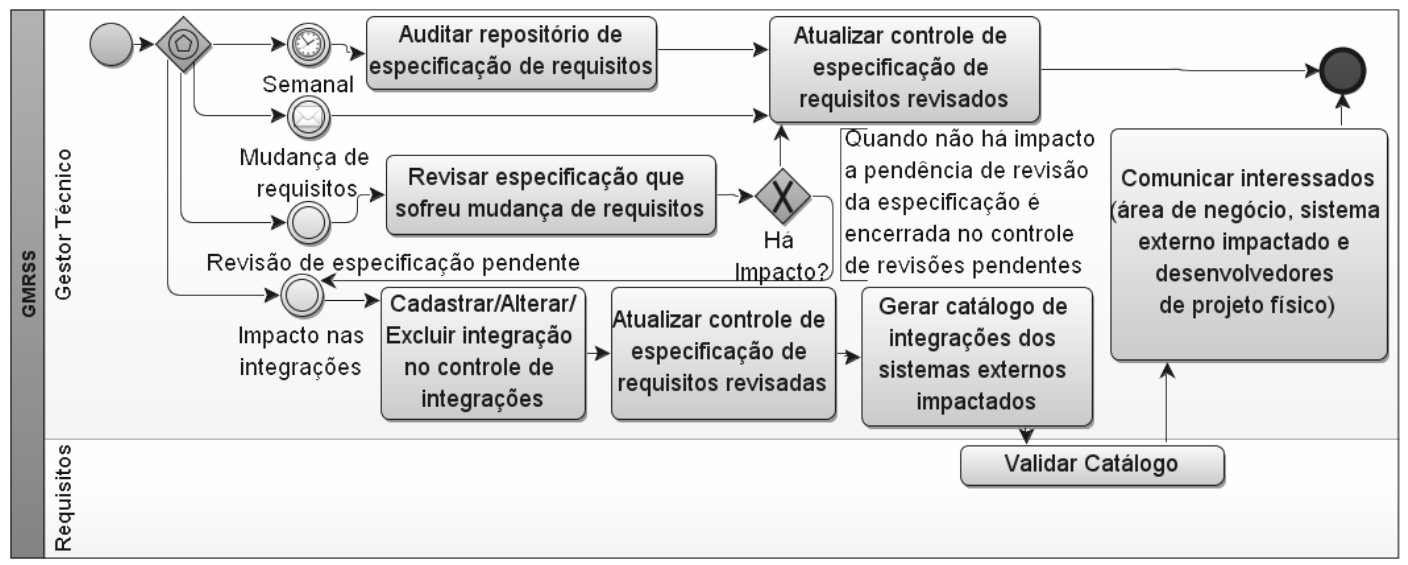

Figura 2. Processo GMRSS

b) Gestão de consumo dos serviços (GECOSE). O processo GECOSE, apresentado na figura 3, retrata os passos essenciais para garantir que os serviços disponibilizados por sistemas de informação externos não deixem de ser priorizados, projetados e integrados a todas as funcionalidades especificadas pelos analistas de requisitos. Mais de uma funcionalidade pode consumir um mesmo serviço. Cabe também a este processo a responsabilidade de comunicar ao Service Provider impedimentos, em especial os tecnológicos e de requisitos, que impossibilitam a realização da integração. Deste modo, busca-se comunicar sistematicamente o Service Provider de modo que ele possa reavaliar os ajustes necessários para atender as necessidades explícitas nas especificações de requisitos. Podemos ilustrar o uso do processo da seguinte maneira: Quando um sistema de informação disponibiliza um serviço de integração, este serviço é encaminhado ao gestor técnico. Este solicita documentos que auxiliem na compreensão semântica e técnica do serviço. Caso o analista de projeto físico detecte que o material disponibilizado é insuficiente para prosseguir com a integração, ele comunica ao gestor técnico que se encarregará de interagir com a equipe que disponibilizou o serviço até que os ajustes necessários sejam concluídos. Em alguns casos os serviços disponibilizados podem requerer parâmetros de entrada não previstos. Nestes casos, os analistas de requisitos devem reavaliar a integração porque novas integrações podem se mostrar necessárias. Em outros casos, integrações especificadas na documentação de requisitos podem se mostrar desnecessárias. Isto pode ocorrer especialmente quando o backlog de atividades dos analistas de requisitos estiver sobrecarregado. Assim, o gestor técnico mantém a integração como "suspensa", alertando os analistas de projetos a não dedicarem esforços nesta atividade. Por fim, quinzenalmente o gestor técnico revisa se existem serviços que foram disponibilizados, porém com pendência de tratamento. Caso existam, os analistas de projeto físico são comunicados sobre os serviços com tratamento pendente, devendo informar ao gestor técnico assim que concluírem a integração. Caso não haja um 
analista responsável, o líder é notificado para alocar um recurso na atividade assim que possível. Nos casos em que é possível alocar um recurso imediatamente, o gestor técnico repassa a atividade para o recurso.

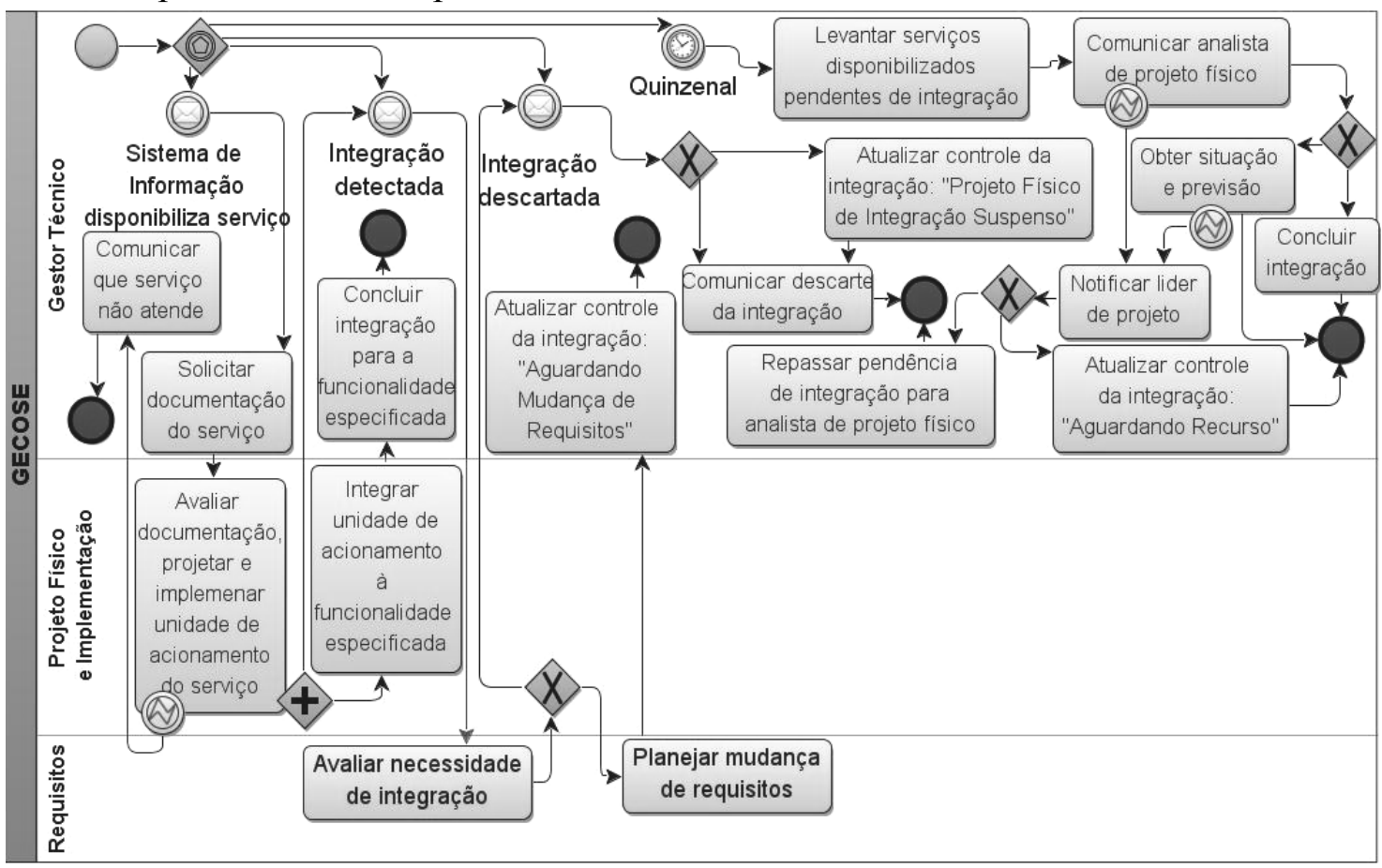

Figura 3. Processo GECOSE

c) Gestão de atendimento a solicitações de serviços (GASS). O processo GASS, apresentado na figura 4, representa os passos essenciais para garantir que serviços que devam ser disponibilizados pelo sistema integrado em construção tenham ordem de implementação em acordo com a área de negócios demandante do projeto. Assim, evita-se o empenho da equipe na construção de serviços com baixa prioridade, bem como o esquecimento da implementação de serviços prioritários. Promove-se ainda que as discussões referentes às prioridades, tanto da equipe do sistema em construção quanto das equipes que desenvolverão serviços para integração, ocorra unicamente em nível de análise de negócio. Podemos ilustrar o uso do processo da seguinte maneira: Quando a equipe de outro sistema de informação pede que um serviço do sistema em construção/manutenção seja disponibilizado, o gestor técnico verifica se existe alguma especificação de requisitos (prevista ou em fase de construção) para o serviço. Caso exista, a previsão de atendimento é informada. Caso não exista, o gestor técnico verifica se existe demanda da área de negócio da empresa solicitando os esforços necessários. Quando existe a demanda, o líder do projeto planeja o atendimento da integração e o gestor técnico posiciona a previsão de atendimento para a equipe do sistema de informação solicitante do serviço. Quando não existe a demanda, o pedido de disponibilização do serviço é encaminhado para a área de negócio da empresa que, após avaliar a solicitação, decidirá pelo não atendimento ou pela criação de uma demanda. Para evitar que haja esquecimento em atender solicitantes de serviços, o gestor técnico levanta pendências de atendimento quizenalmente e as informa ao líder. 


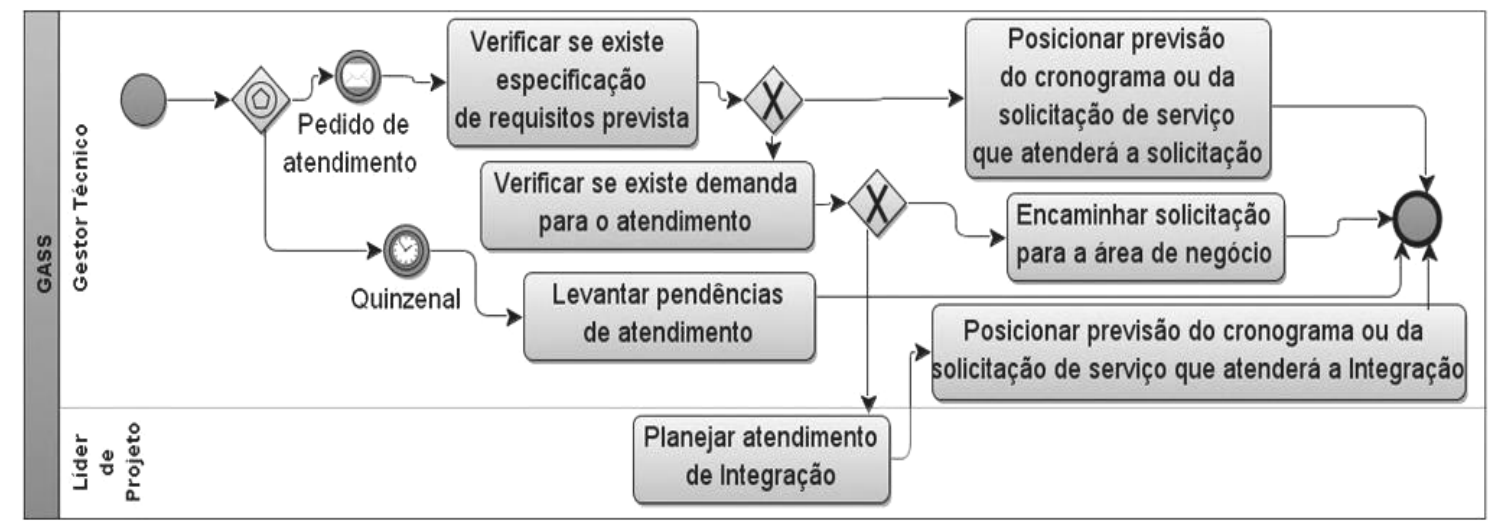

Figura 4. Processo GASS

Em síntese, as integrações são solicitadas pelo processo GMRSS. Tão logo elas sejam disponibilizadas (através de, por exemplo, serviços), o processo GECOSE dá andamento para que elas sejam concluídas. Caso ocorram mudanças de requisitos durante a fase de projeto físico, o processo GMRSS é novamente acionado, dando início a um novo ciclo de integração. Quando o módulo que está em construção deve prover um serviço aos sistemas externos, o controle é feito pelo processo GASS.

Foram desenvolvidas duas ações para facilitar a implantação desses três grupos de processos. A primeira foi a criação da função de Gestor Técnico das integrações. As principais atribuições da função foram a gestão das partes interessadas, ou seja, a busca de apoio de pessoas capazes de influenciar o processo de mudança, a sensibilização e conscientização dos envolvidos, e treinamentos on the job.

A segunda ação para facilitar a implantação foi a construção de uma ferramenta de apoio, responsável por automatizar tarefas repetitivas, gerar eletronicamente relatórios e promover o prosseguimento do fluxo de trabalho estabelecido para o avanço das integrações.

\subsection{Resultados}

Foi constatado, durante a etapa de avaliação dos resultados, uso frequente da ferramenta de apoio: dez profissionais (cerca de $60 \%$ da equipe) responderam utilizar a ferramenta pelo menos duas vezes ao mês. Entre os dez profissionais, quatro responderam utilizar pelo menos nove vezes ao mês. Além disso, nove dos respondentes passaram a usar a ferramenta para consultar reuso de soluções de projeto referentes às integrações. Os respondentes indicaram, ainda, utilizar a ferramenta para rastrear impactos das mudanças de requisitos e acompanhar o histórico de integrações de interesse.

Foi constatado ainda que, para os analistas de projeto físico, a mudança de regras de negócio durante ou após a fase de análise foi interpretada com a barreira de maior destaque. Além desta, e nesta ordem, receberam destaque a falta de documentação adequada, a realização de testes integrados e a indefinição da tecnologia do serviço de integração antes da fase de análise.

Por outro lado, observou-se no histórico de eventos da ferramenta que cerca de 70 novas integrações foram declaradas como concluídas fazendo uso do modelo complementar, mais do que o dobro de integrações que haviam sido concluídas antes da implantação deste. 
Entre as sugestões de melhoria, três integrantes da equipe citaram a realização do projeto físico de uma especificação de requisitos somente quando a maior parte ou a totalidade dos serviços de integração estiverem disponíveis. Dois integrantes citaram que a dificuldade "mudança de requisitos" é inerente ao processo de integração. Outros integrantes citaram ainda que observar variáveis como tipo de tecnologia, homologação da tecnologia pela empresa, relações de integrações que dependem de outras e especificação de cenários de integração em pseudocódigo podem se mostrar úteis.

Por essas considerações é possível sugerir que o modelo complementar e a ferramenta de apoio aprimoraram o controle da IS no ambiente. $\mathrm{O}$ uso frequente da ferramenta e a conclusão de cerca de 70 novas integrações mostra que o modelo é eficaz, entretanto fatores como a padronização e a comunicação sistemática podem ser responsáveis por uma boa parte desses créditos.

Outra discussão está na mudança da forma de trabalho da equipe, posta em evidência pela criação do perfil "gestor técnico". Este passou a concentrar atividades que antes estavam a cargo do líder e dos especialistas. Assim, no mínimo, mudou-se a forma de distribuição das atividades essenciais na IS. Apenas esta mudança poderia impactar na redução de improvisações na IS, gerando reflexos como diminuição de retrabalho.

Nas devidas proporções, cada fator pode ter colaborado também para a observada diminuição na latência de tempo para divulgação às partes interessadas (stakeholders) das evoluções na IS. Casos excepcionais de desvio de comunicação anteriores ao modelo complementar passavam de três semanas de latência até a parte interessada. Não se observou na ferramenta de apoio, mesmo em casos excepcionais, latência de comunicação superior a dez dias.

Outra discussão pertinente é que a geração sistemática de histórico passou a representar, no mínimo, um insumo para apuração de causas de resultados indesejados. Este fator aliado à padronização do processo de controle promove a gestão de conhecimento, ou seja, um novo empregado pode acessar o contexto passado e presente de uma integração, mesmo que, por exemplo, o gestor técnico esteja de férias.

\section{Conclusão e trabalhos futuros}

Por esses resultados, sugere-se a potencial melhoria de eficiência na IS em função da implantação do modelo complementar e da ferramenta de apoio.

Sugere-se ainda que, dadas as dificuldades apontadas pelos respondentes da pesquisa de avaliação, especificar uma integração antes do fechamento de acordos entre os especialistas da equipe que disponibilizam os serviços de integração e os especialistas da equipe que consomem esses serviços pode representar uma prática mais complexa e custosa do que a de não especificar a integração enquanto os acordos entre equipes não forem fechados no nível lógico e técnico.

Recomenda-se, em trabalhos futuros, investigar a utilização dos mecanismos aqui apresentados em outras empresas públicas, de esfera municipal, estadual ou federal para, principalmente, avaliar a validade externa dos resultados obtidos neste caso. É interessante que o profissional que exercerá a função de gestor técnico tenha capacitação técnica, visão gerencial e disponibilidade integral para a prática do intento. 
Além disso, também é interessante que o líder da equipe (gestor) acompanhe de perto as mudanças e tenha equipe receptiva à inovação.

Esta pesquisa analisou os processos de controle relacionados às atividades de IS. Foi possível constatar as dificuldades de gerenciar projetos de IS em órgãos do governo, onde há conflitos entre expectativa e realidade. Nesse sentido, a implementação de um processo que atenda às necessidades do projeto e de uma ferramenta de apoio para acompanhamento se mostraram úteis.

\section{Referências}

Hammer, M. (1990). Reenginering work: Don't automate, obliterate. Harvard Bus.Rev., July-Aug., 104-112.

Hammer, M., \& Champy, J. (1993). Reenginering the Corporation. Harper Business, New York.

Huang, Z., \& Bwoma, P. O. (2003). An overview of critical issues of E-government. Issues of Information Systems, 4(1), 164-170. Retrieved from http://iacis.org/iis/2003/HuangBwoma.pdf

Kamal, M. M., \& Themistocleous, M. (2006). A conceptual model for EAI adoption in an e-government environment. Information Systems, 1-11. EMCIS2006. Retrieved from http://dspace.brunel.ac.uk/handle/2438/4018

Mili, H., Tremblay, G., Jaoude, G. B., Lefebvre, E., Elabed, L., \& Boussaidi, G. E. (2010). Business process modeling languages: Sorting through the alphabet soup. ACM Computing Surveys (CSUR), 43(1), 4. ACM. Retrieved from http://dl.acm.org/citation.cfm?id=1824799

Rossetto, A. M., Orth, D., \& Rossetto, C. R. (2004). Implicações de variáveis organizacionais na adoção de inovações tecnológicas em organizações públicas: estudo de caso de implantação de sistema de informações geográficas em prefeitura de médio porte. Revista da Administração Pública, 38, 109-36.

Santos, H. , Santana, A., Alves, C. (2011) "Análise de Fatores Críticos de Sucesso da Gestão de Processos de Negócio em Organizações Públicas", VIII Congresso Brasileiro de Sistemas de Informação - SBSI 2012, São Paulo, Brasil.

Saraiva, Luiz, \& Capelão, Luiz (2000). "A nova administração pública e o foco no cidadão : burocracia X marketing ?" Revista da Administração Pública, 32, 55-77.

Sommerville, I., \& Melnikoff, S. (2003). Engenharia de software. Retrieved from http://scholar.google.com.br/scholar?hl=pt-

BR\&as_sdt $=0 \& \mathrm{q}=$ engenharia $+\mathrm{de}+$ software + sommerville\# 1

WfMC (1999). Workflow Management Coalition. Terminology and glossary, document WfMC-TC-1011. Retrieved from http://www.wfmc.org/standards/docs/TC1011_term_glossary_v3.pdf.

Yin, R. K. (2005) Estudo de caso planejamento e métodos, $3^{a}$ edição. Porto Alegre: Bookman. 